\title{
Factors Influencing Teachers' Use of Multimedia Enhanced Content in Secondary Schools in Tanzania
}

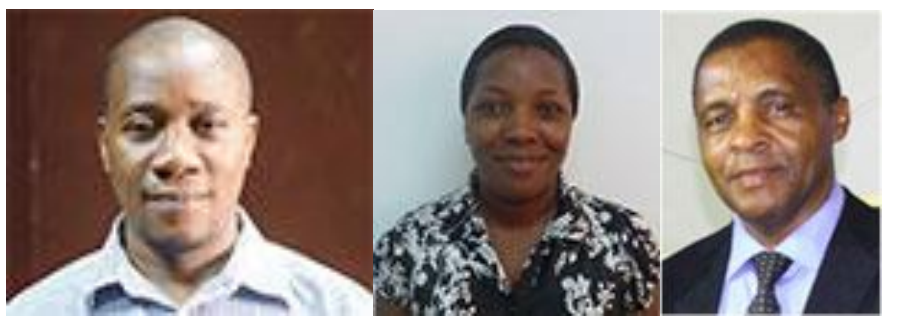

Joel S. Mtebe, Betty Mbwilo, and Mussa M. Kissaka

University of Dar es Salaam, Tanzania

\begin{abstract}
Tanzania is faced with a severe shortage of qualified in-service school science and mathematics teachers. While science and mathematics account for $46 \%$ of the curriculum, only $28 \%$ of teachers are qualified to teach these subjects. In order to overcome this challenge, the Ministry of Education and Vocational Training (MoEVT) implemented a project to use multimedia-enhanced content to upgrade subject content knowledge of science and mathematics teachers in secondary schools. A total of 70 topics and 147 subtopics were developed and enhanced with various multimedia elements. The content was used to train 2,00o in-service science and mathematics teachers from secondary schools in 19 selected centers countrywide. However, the presence and availability of this content does not automatically guarantee that teachers will use them. For this content to improve teachers' subject content knowledge, they must be accepted and used by teachers in secondary schools. This study examines factors affecting teachers' acceptance and prolonged use of developed multimedia-enhanced content using the extended Unified Theory of Acceptance and Use of Technology (UTAUT2) as a research framework. A sample of 1,137 teachers out of 2,000 was collected and tested against the research model using regression analysis. With exception of performance expectancy, all other factors had a statistically significant effect on teachers' acceptance and use of the developed content. The government and other stakeholders can use these findings to develop strategies that will promote acceptance and use of the developed content in secondary schools in Tanzania.
\end{abstract}

\section{Introduction}


In recent years, there has been an increasing interest in the development and use of multimediaenhanced content to enhance the quality of teaching and learning. The multimedia content are digital instructional materials that combine text, graphics, audio, and animations. Teachers tend to use these content to liven up classroom lectures by using them to better demonstrate and explain difficult concepts that cannot be easily explained using text alone (Lanzilotti et al., 2006; Thomas \& Israel, 2013).

Studies have indicated that the appropriate use of multimedia-enhanced content in educational context provides several benefits. They can help to improve students' understanding of instructional materials (Lee, Hsiao, \& Ho, 2014). They can also simulate real processes such as motion, diffusion, or bonding atoms and allow learners to execute virtual experiments that would be dangerous and costly to be conducted in a school laboratory (Hennessy, Deaney, \& Ruthven, 2006).

In light of the above benefits, the Ministry of Education and Vocation Training (MoEVT) in collaboration with the College of Information and Communication Technologies (CoICT) of the University of Dar es Salaam implemented a pilot project to use multimedia-enhanced content to upgrade subject content knowledge of science and mathematics teachers. Specifically, the project aimed at upgrading subject content knowledge of teachers in selected difficult topics in mathematics, physics, biology, and chemistry at ordinary level (Form I to Form IV) secondary education in Tanzania.

The project is part of the government's efforts to address the current severe shortage of qualified inservice science and mathematics teachers in Tanzania. According to a World Bank project paper ("Tanzania science and technology" , 2014), of the current 10,400 in-service secondary school science and mathematics teachers, many do not have sufficient subject content knowledge of the subjects they teach. While science and mathematics account for $46 \%$ of the curriculum, only $28 \%$ of teachers are qualified to teach these subjects. This lack of subject content knowledge of teachers has been affecting students' achievement in science and mathematics in secondary education in Tanzania.

This lack of subject content knowledge of teachers has been evident by a steady decrease in students' pass rate of these subjects in ordinary level secondary schools in Tanzania for the past few years. For instance, the pass rates of physics was $26.3 \%$ in 2008 and dropped to $13.7 \%$ in 2011 while that of chemistry was $32.9 \%$ in 2008 and dropped to $15.8 \%$ in 2011 (Ministry of Education and Vocational Training, 2012). Similarly, the pass rate of biology dropped from $15.1 \%$ in 2008 to $9.4 \%$ in 2011 while that of mathematics dropped from $9.2 \%$ in 2008 to $5.8 \%$ in 2011.

It is widely recognized that for developing countries like Tanzania, to train teachers as well as develop their academic knowledge and professional skills to the level required to ensure effective secondary education is a major undertaking (Leach, 2005). In this regard, MoEVT sought to improve subject content knowledge of teachers in secondary schools through adoption and use of multimediaenhanced content. The multimedia-enhanced content was developed by a team of technical experts from CoICT in collaboration with teachers from selected secondary schools in Tanzania.

A total of 70 topics and 147 subtopics were developed and enhanced with various multimedia elements (animations, videos, and audio). This content was used to train 2,000 science teachers from 
secondary schools in 19 selected centers countrywide. Sixty facilitators from four universities who had the subject knowledge and training experience were tasked to train teachers in these centers.

After the training, teachers were given Digital Versatile Discs (DVDs) containing the developed content so that they can continue to learn the difficult concepts and improve their subject content knowledge at home. The same content was made available online through the customized Moodle Learning Management System accessible via http://retooling.udsm.ac.tz. Teachers were registered and given access to use the system anytime, anywhere via the Internet.

However, the presence and availability of this content does not automatically guarantee that teachers are going to use them. For this content to improve teachers' subject content knowledge, they must be accepted and used by teachers. A number of studies have indicated that the successful pedagogical use of technology depends on teachers' attitudes and acceptance towards that technology (Wong, Osman, Goh, \& Rahmat, 2013).

Therefore, it is important for all stakeholders involved in the project to know whether the future use of the multimedia-enhanced content by teachers can be predicted. Venkatesh, Thong, Chan, Hu, and Brown (2011) point out that the pre-usage beliefs might serve as anchors for post-usage beliefs as people tend to rely on their initial beliefs and early impressions in the formation of future beliefs. In this regard, it is very important to determine teachers' perceptions and beliefs with the multimediaenhanced content just after the training in order to find strategies that will maximize its usage.

This study intended to examine factors influencing acceptance and continual use of developed multimedia-enhanced content in secondary schools in Tanzania. A questionnaire was prepared and distributed to 2,000 teachers in 19 centers. A total of 1,137 teachers were able to fill in the data instrument. The data were then tested against the research model using regression analysis. The study adopted the extended unified theory of acceptance and use of technology (UTAUT2) model (Venkatesh, Thong, \& Xu, 2012) as a theoretical framework.

\section{Adoption of ICT in Teachers' Professional Development}

Teacher professional development is said to play a significant role in improving the quality of teaching and learning in any educational context. Avalos ( 2011) defines professional development as teachers learning, learning how to learn, and transforming their knowledge into practice for the benefit of their students' growth. Shulman (1987) categorized three types of knowledge required by teachers to be able to provide quality teaching in any given educational setting. These types of knowledge include subject knowledge, school knowledge, and pedagogical knowledge.

The use of ICT can enable teachers to have access to the knowledge and expertise that was previously unavailable, hence contributing towards teachers' professional development (Vrasidas \& Glass, 2005). Leach (2005) provides a detailed analysis on how ICT can be used in teachers' professional development. The author points out that ICT can enhance teachers' subject knowledge by providing teachers with resources that support professional enquiry, such as Internet access to a range of high quality, subject-focused multimedia resources related to the project's content. 
Leach (2005) further added that ICT can also improve the quality of teachers” pedagogical knowledge. For example, multimedia can enhance the way learners research a topic, and present their findings to others; therefore, support for sound, animation and video is also seen as highly advantageous. ICT can also upgrade teacher school knowledge, access to classroom planning and resources, exemplar curriculum activities, as well as to professional networks and tools that facilitate the sharing of practice.

Despite the role of ICT in teacher professional development, some challenges still exist that hinder teachers from using such technologies. Prestridge (2012) has grouped these barriers into two main groups: first order and second order barriers. He described first order barriers as those extrinsic to the teacher that include lack of resources, time, access, and technical support to use the technologies. On the other hand, the second-order barriers are those related to the teachers' beliefs and attitudes on the use of ICT for teaching and learning.

A number of studies have indicated that teachers' attitudes and acceptance towards technology directly influences the acceptance, continual use, and integration of such technologies in teaching. In this regard, several studies such as those in Davis (1989), and Venkatesh et al. (2003, 2012) have investigated various factors that influence users in accepting and using various technologies. In this study, UTAUT2 was adopted.

\section{Theoretical Framework}

The UTAUT2 model was adopted and extended to examine teachers' acceptance and continual use of multimedia-enhanced content. The model was an extension of the UTAUT model of 2003. The main modifications made to the original model are the inclusion of three new constructs namely price value, hedonic motivation, and habit making a total of seven constructs.

The seven constructs have been hypothesized to have direct determinants of usage intention and behavior. The variables-gender, age, experience, and voluntariness of use-moderate the key relationships in the model. The UTAUT2 model is shown in Figure 1. 


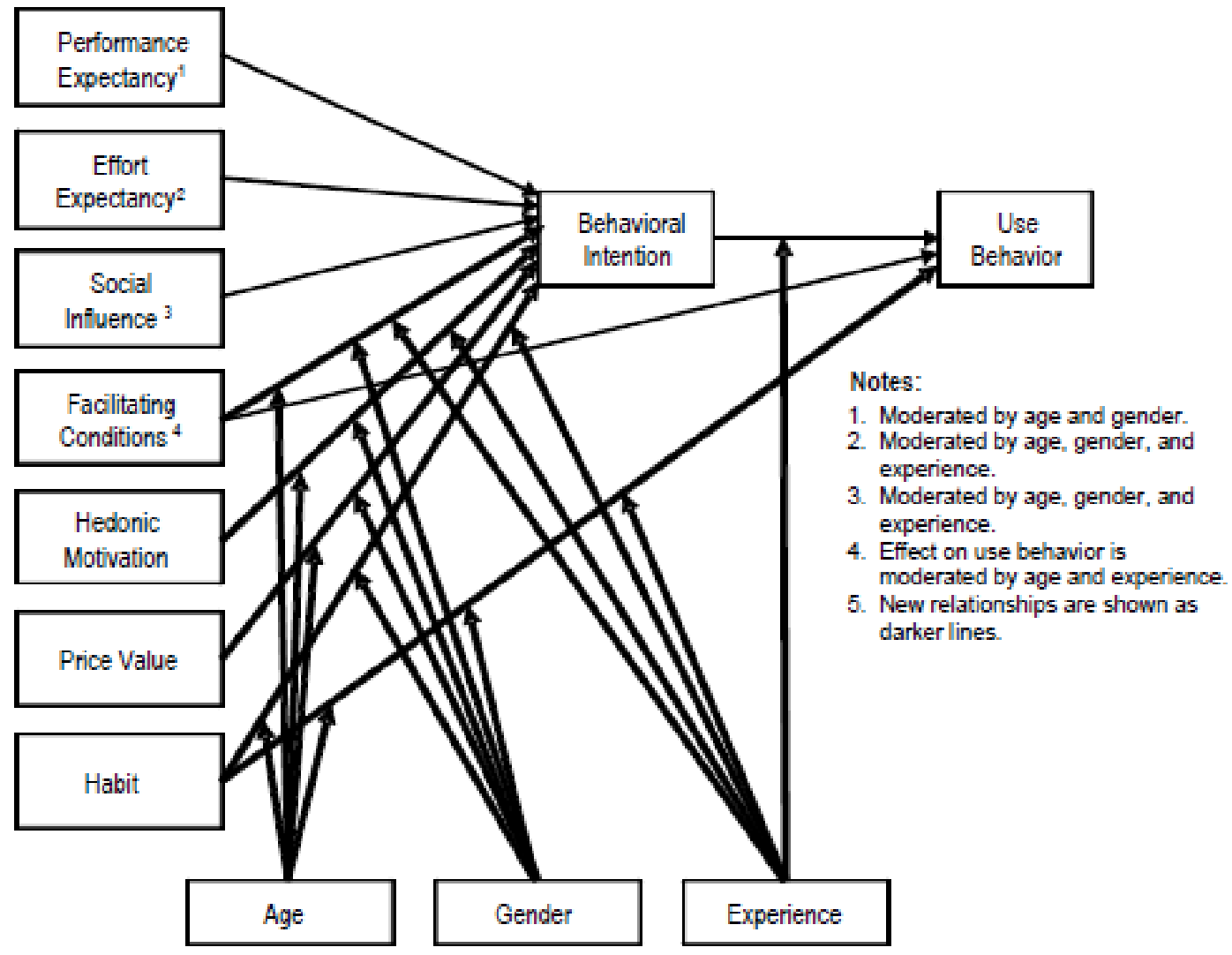

Figure 1. The UTAUT model. Source: Venkatesh et al., 2012 (p.160).

Venkatesh et al. (2012) define the constructs:

- Performance expectancy is defined as the "degree to which using a technology will provide benefits to consumers in performing certain activities" (p. 159).

- Effort expectancy is defined as the "degree of ease associated with consumers' use of technology" (p. 159).

- Social influence is defined as the "extent to which consumers perceive that important others (e.g., family and friends) believe they should use a particular technology" (p. 161).

- Hedonic motivation is defined as the "fun or pleasure derived from using a technology, and it has been shown to play an important role in determining technology acceptance and use" (p. 161).

- Price value is defined as the cost consumers incur as a result of using a certain technology.

- Habit is defined as "the extent to which people tend to perform behaviors automatically because of learning” (p. 161).

Compared to UTAUT, UTAUT2 produced a substantial improvement in the variance explained in behavioral intention (56\% to $74 \%$ ) and technology use (40\% to $52 \%$; Venkatesh et al., 2012). It is therefore logical to use this model to investigate factors that influence teachers from accepting and using multimedia-enhanced content in Tanzania.

\section{Research Model and Hypotheses}


In adapting the UTAUT2 model for this research, the price value construct was excluded. This is because despite the fact that the multimedia content was shared via the Learning Management System (LMS), teachers were given the same copy of content in form of DVDs. It is clear that the majority of teachers are expected to use the content via DVDs compared to accessing it through the LMS due to unavailability and unreliability of Internet connectivity especially in rural secondary schools in Tanzania. The moderation factors were dropped in the model due to the fact that the study was not intended to investigate the effect of gender, age or experience in the acceptance and use of multimedia-enhanced content. The research model is shown Figure 2.

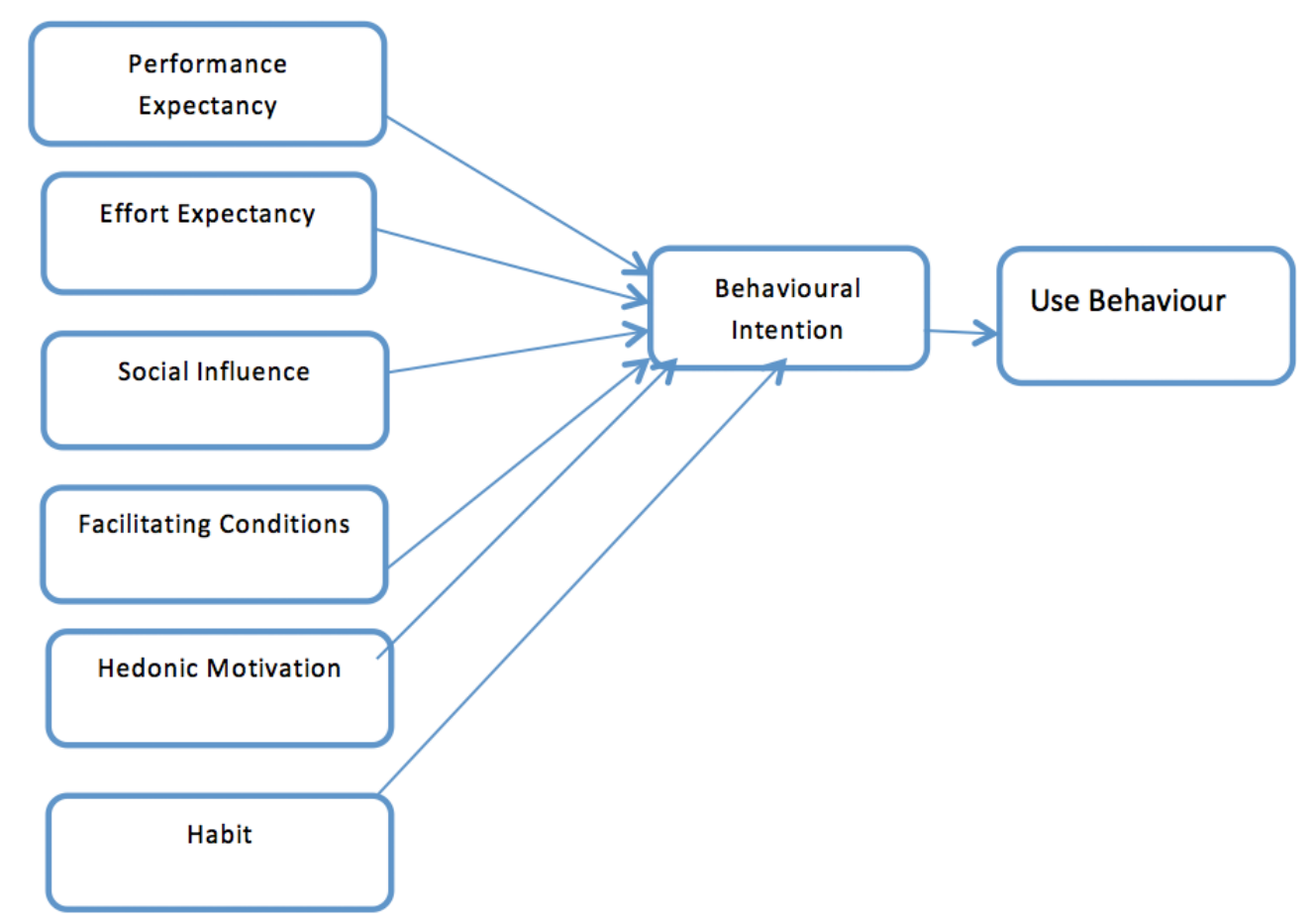

Figure 2. Research model.

The construct and the hypotheses are described next.

\section{Performance Expectancy}

Performance expectancy is defined as the degree to which users believe that using a certain technology will enable them to accomplish activities more quickly and efficiently. It is the strongest predictor of acceptance and use of several applications in both voluntary and involuntary settings (Venkatesh et al., 2003). In the context of this study, it represents the degree to which teachers believe that using multimedia-enhanced content will enable them to perform teaching activities much better than before. Strengthening this belief will increase teachers' acceptance and use of multimedia-enhanced content. Therefore, the hypothesis is derived as follows:

Hypothesis 1-performance expectancy has an effect on teachers' acceptance and use of multimedia-enhanced content. 


\section{Effort Expectancy}

Effort expectancy is the degree of ease associated with consumers' use of technology (Venkatesh et al., 2012). When a technology is perceived to be easy to use, users intend to use and continue using it (Xu, Lin, \& Chan, 2012). In this study, Effort expectancy represents teachers' perception that using the multimedia-enhanced content will be easy and effortless. It is expected that acceptance and continual use of multimedia-enhanced content will depend on whether teachers perceive the content as easy to use and free of effort. Therefore, the proposition is derived as follows:

Hypothesis 2-effort expectancy has an effect on teachers' acceptance and use of multimediaenhanced content.

\section{Social Influence}

Social Influence is the extent to which users perceive that important others (e.g., family and friends) believe they should use a particular technology (Venkatesh et al., 2012). In the context of this study, it represents the degree to which teachers perceive that others believe they should use multimediaenhanced content. According to social influence theory, users tend to comply with other important referees' opinions (Bagozzi \& Lee, 2002). Therefore, when people who are important to the teachers (such as headmasters, colleagues) recommend they use multimedia-enhanced content, they are likely to follow their suggestions. In this regard, it is important to include social influence as one of the constructs in the modified research model. The proposition is derived as follows:

Hypothesis 3-social influence has a positive effect on teachers' acceptance and use of multimedia-enhanced content.

\section{Facilitating Conditions}

Facilitating conditions are defined as the degree to which users believe that an organizational and technical infrastructure exists to support use of a certain technology (Venkatesh et al., 2003). In this context, it refers to teachers' perceptions of the availability of resources and support to use multimedia-enhanced content. These resources include availability of computers that can be used to access DVDs, reliable Internet connection to access the LMS, and other related resources. Therefore, teachers' decision to accept and continue use of multimedia-enhanced content will be influenced by his or her perception on the availability of these resources. The proposition is derived as follows:

Hypothesis 4-facilitating conditions has an effect on teachers' acceptance and use of multimedia-enhanced content.

\section{Habit}

Habit is the tendency to automatically use a technology as a result of learned behavior (Venkatesh et al., 2012). In addition, Venkatesh and his colleagues describe habit as having both a direct effect on use and an indirect effect through behavioral intention. In this study, habit is the extent to which teachers tend to use multimedia-enhanced content automatically because of learning. It is expected that teachers will have a habit of using multimedia-enhanced content after they have interacted with and are familiar with the content in both LMS and DVDs. The proposition is derived as follows: 
Hypothesis 5 -habit has an effect on teachers' acceptance and use of multimedia-enhanced content.

\section{Hedonic Motivation}

Hedonic motivation is defined as the fun or pleasure derived from using a certain technology (Venkatesh et al., 2012). Users normally attach importance to good or happy feelings resulting from using the technology (Xu et al., 2012). Therefore, teachers will accept and continue to use the developed multimedia-enhanced content if they feel good or happy when using them.

Hedonic motivation is a critical determinant of behavioral intention and was found to be a more important driver than performance expectancy in non-organizational contexts (Venkatesh et al., 2012). If teachers cannot obtain enjoyment from using multimedia-enhanced content, they may discontinue their usage due to an unpleasant experience.

Hypothesis 6-hedonic motivation has an effect on teachers' acceptance and use of multimedia-enhanced content.

\section{Behavioral Intention}

Venkatesh et al. (2003) suggest that behavioral intention to use a given technology has significant influence on usage behavior. In this study, the behavioral intention has been adapted as an independent variable to measure teachers' acceptance and use of multimedia-enhanced content.

\section{Research Methodology}

\section{Data Collection Instrument}

The study adopted a research instrument developed by Venkatesh et al. (2012) that uses a 5-point Likert scale ranging from 1 (strongly disagree) to 5 (strongly agree). The data collection instrument was re-worded and modified to suit the context of this study. Table 1 shows part of the data instrument used to collect data (excluding the demographics).

Table 1

The UTAUT Items Construct

\begin{tabular}{lcl}
\hline Construct & Code & Item \\
\hline $\begin{array}{l}\text { Performance } \\
\text { expectancy }\end{array}$ & PE1 & $\begin{array}{l}\text { I find multimedia-enhanced content useful in teaching in science and } \\
\text { mathematics subjects. }\end{array}$ \\
& PE2 & $\begin{array}{l}\text { Using multimedia-enhanced content enables me to accomplish } \\
\text { learning activities more quickly. }\end{array}$
\end{tabular}


PE3 Using multimedia-enhanced content increases my knowledge in teaching science and mathematics subjects.

PE4 Using mobile Internet increases my skills for teaching science and mathematics subjects.

Effort expectancy

EE1 My interaction with multimedia-enhanced content is clear and understandable.

EE2 Learning how to use multimedia-enhanced content is easy for me.

EE3 I find multimedia-enhanced content easy to use

EE4 It is easy for me to become skillful at multimedia-enhanced content.

Social influence

SI1 People who influence my behavior will think that I should use multimedia-enhanced content.

SI2 People who are important to me will think that I should use multimedia-enhanced content.

SI3 People whose opinions that I value prefer that I use multimediaenhanced content.

Facilitating

FC1 I have the resources (e.g. PC, Internet etc.) necessary to use conditions multimedia-enhanced content.

FC2 I have the knowledge necessary to use the multimedia-enhanced content.

FC3 Multimedia-enhanced content is similar to other tools I use in teaching science and mathematics subjects.

FC4 A help is available when I get problem in using multimedia-enhanced content.

Hedonic

HM1 Using multimedia-enhanced content is fun.

motivation

HM2 Using multimedia-enhanced content is enjoyable.

HM3 Using multimedia-enhanced content is very entertaining.

Habit

H1 The use of multimedia-enhanced content has become a habit for me.

H2 I am addicted to using multimedia-enhanced content.

H3 I must use multimedia-enhanced content. 
Behavioral

intention

BI1 I intend to continue using multimedia-enhanced content in the future.

BI2 I will always try to use multimedia-enhanced content in my daily life.

BI3 I plan to continue to use multimedia-enhanced content frequently.

Note. Scale labels: 1 - Strongly Disagree, 2 - Disagree, 3 - Neutral, 4 -Agree, 5 - Strongly Agree

\section{Data Collection}

The questionnaire was printed and distributed to 2,000 teachers in 19 centers in the country. Teachers were asked to fill in the instrument at the end of the training. The questionnaire was selfadministered. All respondents were guaranteed confidentiality and the name field was treated as optional.

A total of 1,137 teachers completed questionnaires out of 2,000 teachers. This is $56.9 \%$ of all respondents. The data collection was undertaken between March to April 2015. The data were analyzed using Statistical Packages for Social Science (SPSS) version 20.

\section{Demographic Information}

Of the study population, $16.4 \%$ (187) were physics teachers, $26.1 \%$ (297) chemistry teachers, $21.1 \%$ (240) mathematics teachers, and $36.3 \%$ (413) biology teachers. Figure 3 shows the distribution of teachers per subjects they teach.

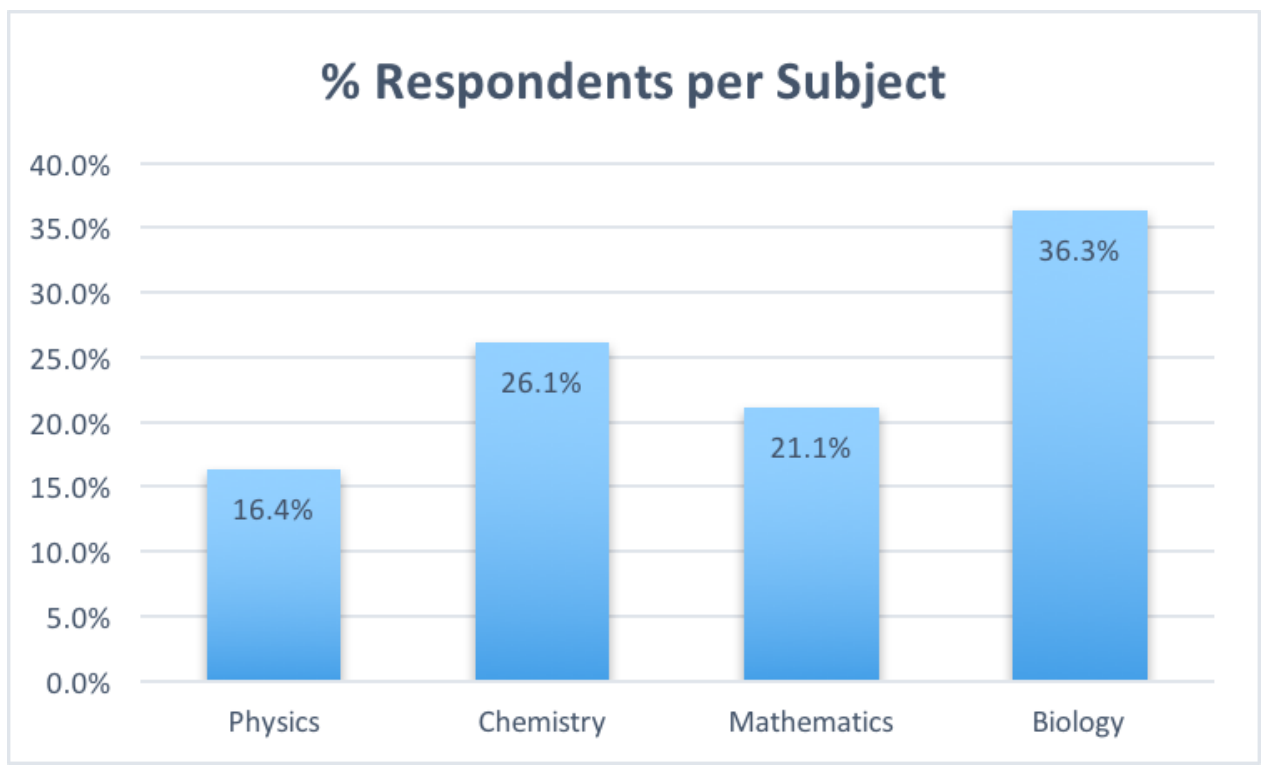

Figure 3. Respondents' demographic profile per subject.

The demographic information also shows that the majority of respondents were from Dar es Salaam region with $23.8 \%$ followed by Mbeya region with 21.2\%. Kigoma region had the least number of respondents with $0.9 \%$ followed by the Urban West and North Unguja regions with $1.9 \%$ of respondents. The distribution of respondents per region is shown in Table 2. 
Table 2

The Distribution of Respondents Per Region

\begin{tabular}{lll}
\hline Region & Frequency & Percent \\
\hline Arusha & 46 & 4 \\
Dar es Salaam & 271 & 23.8 \\
Geita & 99 & 8.7 \\
Kigoma & 10 & 0.9 \\
Mbeya & 241 & 21.2 \\
Morogoro & 132 & 11.6 \\
Mtwara & 67 & 5.9 \\
North Pemba & 65 & 5.7 \\
North Unguja & 22 & 1.9 \\
Shinyanga & 72 & 6.3 \\
South Pemba & 65 & 5.7 \\
South Unguja & 25 & 2.2 \\
Urban West & 22 & 1.9 \\
\hline
\end{tabular}

\section{Research Results}

\section{Reliability and Validity}

Reliability is used to ensure the consistency of the results for the various items being tested within each component (Foster, 2001). It is normally evaluated by assessing the internal consistency of the items representing each construct using Cronbach alpha (Cronbach, 1951). Based on the SPSS results, the Cronbach alpha coefficient for the 24-item instrument was .931. The value of Cronbach's Alpha should be positive and even greater than .700 (Nunnally, 1978). As shown in Table 3, Cronbach alpha value for seven constructs are above .700 . Therefore, the instrument used for this study was reliable. The overall questionnaire was considered valid as it used the same items from previous surveys.

Table 3

Cronbach's Alpha Coefficients for Construct Reliability Measurement

Construct $\quad$ Cronbach's alpha $(\alpha)$




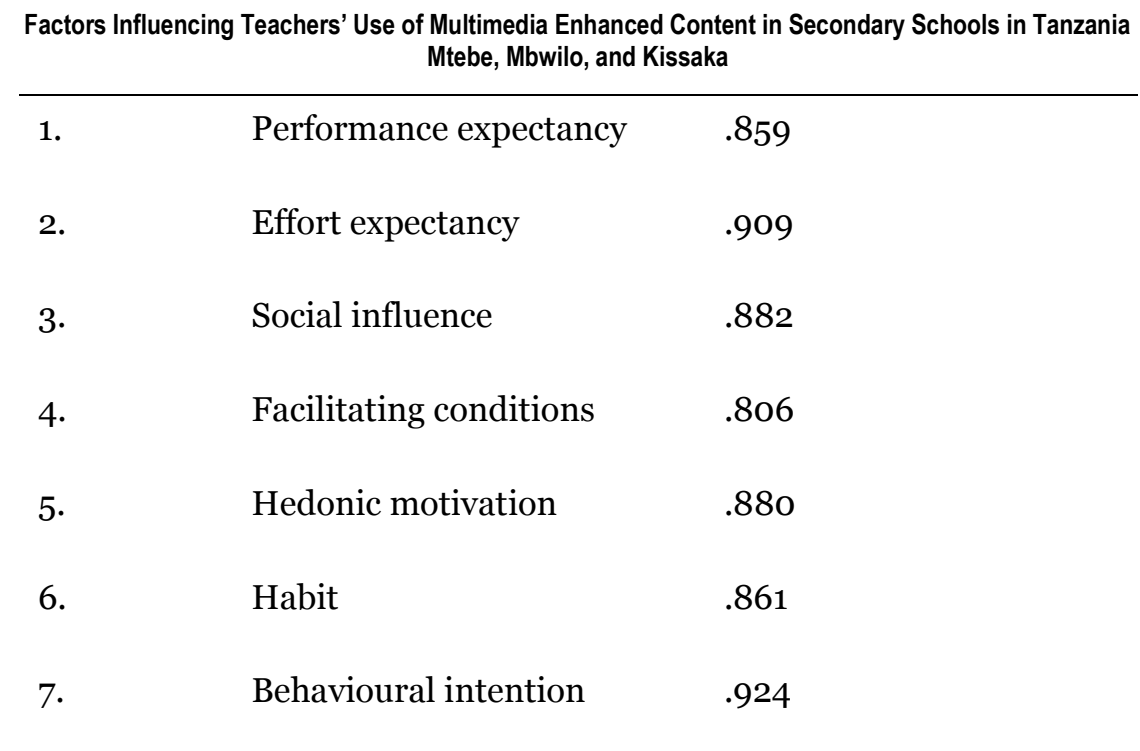

\section{Sampling Adequacy}

The Kaiser-Meyer-Olkin measure of sampling (KMO) was used to measure the sampling adequacy of the data. According to Kaiser (1973), the KMO below .50 is unacceptable and factor analysis should not be performed. In this study, the KMO was .900 and confirmed the sampling adequacy. Moreover, Bartlett's test of sphericity $\mathrm{p}<.001$, indicated that the correlation between items was sufficiently large for performing the principal component analysis (PCA).

\section{Identifying the Factor Structure}

Factor analysis (FA) was performed using the principal component analysis extraction method on 24 items using direct oblimin rotation with Kaiser normalization. The aim of the FA was to show whether the related items were clustered under the same construct or not. The minimum factor loadings should be .300 (Hair, Black, Babin, \& Anderson, 2009). The loadings per each item are shown in Table 4. All items in the research instrument loaded successfully.

Table 4

Factor Loadings on the UTAUT Construct Items

\begin{tabular}{llllllll}
\hline & PE & EE & SI & FC & HM & Habit & BI \\
& & & & & & & \\
\hline PE1 & .741 & & & & & & \\
PE2 & .853 & & & & & & \\
PE3 & .897 & & & & & & \\
PE4 & .857 & & & & & & \\
EE1 & & -.857 & & & & & \\
EE2 & & -.903 & & & & & \\
\end{tabular}




\begin{tabular}{|c|c|c|c|c|c|}
\hline EE3 & -.901 & & & & \\
\hline EE4 & -.885 & & & & \\
\hline SI1 & -.889 & & & & \\
\hline SI2 & -.939 & & & & \\
\hline $\mathrm{SI} 3$ & -.869 & & & & \\
\hline $\mathrm{FC} 1$ & & .815 & & & \\
\hline $\mathrm{FC} 2$ & & .873 & & & \\
\hline $\mathrm{FC}_{3}$ & & .814 & & & \\
\hline $\mathrm{FC}_{4}$ & & .662 & & & \\
\hline HM1 & & & .895 & & \\
\hline HM2 & & & .945 & & \\
\hline $\mathrm{HM}_{3}$ & & & .846 & & \\
\hline H1 & & & & -.896 & \\
\hline $\mathrm{H} 2$ & & & & -.94 & \\
\hline $\mathrm{H}_{3}$ & & & & -.806 & \\
\hline BI1 & & & & & .916 \\
\hline BI2 & & & & & .959 \\
\hline $\mathrm{BI} 3$ & & & & & .903 \\
\hline
\end{tabular}

\section{Research Model Summary}

Six factors were subjected to linear regression analysis to measure the success of the model and predict causal relationship between the factors and behavioral intention. The six factors are performance expectancy, facilitating conditions, effort expectancy, hedonic motivation, habit, and social influence. Using enter method, a significant model emerged: $\mathrm{F}(6,1130)=128.429, p<.0005$.

The model explains $40.2 \%$ of the variance (adjusted $R^{2}=.402$ ) in teachers' behavioral intention to accept and use multimedia-enhanced content. Table 5 shows a summary of the research model.

Table 5

Summary shows the success of the research model

Model $\quad R \quad R^{2} \quad$ Adjusted $R^{2} \quad S E$




\begin{tabular}{llll}
\hline 637 & .405 & .402 & .773
\end{tabular}

Note. $S E=$ standard error of the estimate.

Table 6 shows a summary of predictive factors in terms of beta values for each hypothesis obtained from regression analysis. The results show that performance expectancy did not have significant effect on teachers' behavioral intention to accept and use of multimedia-enhanced content.

Two factors: Hedonic Motivation and Facilitating Conditions have shown to have positive significant effect on teachers' behavioral intention to adopt and use of multimedia-enhanced content. However, Effort Expectancy, Social Influence, and Hedonic Motivation have shown to have negative significant effect on the behavioral intention to accept and use of multimedia-enhanced content. The beta values are shown in Table 6.

Table 6

Unstandardized and Standardized Regression Coefficients for the Constructs Entered in the Model

\begin{tabular}{lllll}
\hline Construct & $\mathrm{B}$ & $\mathrm{SE}$ & $\beta$ & $p$ \\
\hline $\mathrm{PE}$ & .02 & .027 & .02 & .454 \\
$\mathrm{FC}$ & .148 & .026 & .148 & .000 \\
$\mathrm{EE}$ & -.062 & .03 & -.062 & .038 \\
$\mathrm{SI}$ & -.111 & .028 & -.111 & .000 \\
$\mathrm{HM}$ & .347 & .026 & .347 & .000 \\
$\mathrm{H}$ & -.198 & .026 & -.198 & .000 \\
\hline
\end{tabular}

A summary of how the hypotheses have been tested is shown in Table 7.

Table 7

Summary of Results Hypothesis Testing

\begin{tabular}{llll}
\hline & & Results & Conclusion \\
\hline Hypothesis 1 & $\begin{array}{l}\text { Performance expectancy has } \boldsymbol{\beta}=.02, \mathrm{p}<.454 \\
\text { significant effect on teachers' } \\
\text { acceptance and use of } \\
\text { multimedia-enhanced content. }\end{array}$ & $\begin{array}{l}\text { Not } \\
\text { Supported }\end{array}$ \\
& Effort expectancy has $\boldsymbol{\beta}=-.062, \mathrm{p}<.05$ & Supported
\end{tabular}


significant effect on teachers'

acceptance and use of

multimedia-enhanced content.

Hypothesis 3

Hypothesis 4

Hypothesis 5

Hypothesis 6
Facilitating conditions has

significant effect on teachers'

acceptance and use of

multimedia-enhanced content.

Social Influence has significant

effect on teachers' acceptance

and use of multimedia-

enhanced content. $\beta=.148, p<.001 \quad$ Supported

$\beta=-.111, p<.001$

Supported

$\boldsymbol{\beta}=.347, \mathrm{p}<.001 \quad$ Supported

significant effect on teachers'

acceptance and use of

multimedia-enhanced content.

Habit has significant effect on

teachers' acceptance and use of

multimedia-enhanced content.

$\beta=-.198, p<.001 \quad$ Supported

Note. Statistically significant values at $\mathrm{p}<.05$ or $\mathrm{p}<.001$

\section{Discussion}

Many developing countries such as Tanzania have been facing difficulties not only to train enough new teachers to meet the demands of secondary education, but also to upgrade the skills and competences of in-service teachers (Leach, 2005). Studies have consistently shown that the appropriate adoption and use of ICT can help developing countries train more teachers via ICTmediated distance learning as well as equipping teachers with the required skills to improve the quality of education.

In view of the fast rate of technological development, the MoEVT in collaboration with CoICT decided to develop multimedia-enhanced content in order to upgrade the subject content of teachers in science and mathematics in secondary education in the country. The teachers were trained on how to access the content in the LMS as well as on how to use the DVDs. Nonetheless, for the content to be able to enhance their subject content knowledge goes beyond its sole availability. Factors affecting teachers' initial acceptance and their future behavior regarding the use these technologies need to be addressed.

This study examined factors influencing the continual use of developed multimedia-enhanced content in secondary schools in Tanzania. The study used effort expectancy to determine how much 
teachers believed that using multimedia-enhanced content will be easy and free of effort. The finding indicated that teachers perceived that these contents would not be easy to use. This is due to the fact this construct had negative influence $(\beta=-0.062)$ on teachers acceptance and use of the content. Those who are involved in the project implementation need to take urgent action to overcome this problem. This is because if users perceive that the effort required in using a technology is high, then the chances of those individuals adopting the relevant technology will be low, and vice versa (Percy \& Belle, 2012; Xu et al., 2012).

This finding suggests that the training that was conducted for 10 days in selected centers was not enough to enable teachers to use the DVDs, the LMS, or both effectively. Clearly, more training was needed and those who are involved in this project should find ways to conduct more training to teachers who are already using the content. However, as teachers continue to use the content after the training, their perceptions about ease of use will change. Venkatesh (2000) suggests that after direct experience in using the technology, perceptions about ease of use would be adjusted to reflect various aspects of the experience. Therefore, with increasing experience of using the content, it is expected that teachers will perceive the content as easy to use and free of efforts.

An unexpected vital and interesting finding to emerge from this study was that facilitating conditions had a positive significant effect ( $\beta=0.148$ ) on teachers' acceptance and use of multimedia-enhanced content. The finding implies that teachers believed they had resources necessary to use the developed content. These resources include computers that can be used to access DVDs, Internet connection to access the LMS, and the knowledge to use them.

This finding was somewhat surprising as many studies have shown that teachers in rural secondary schools do not have access to computers and the Internet. The possible explanation of this result could be due to the fact that teacher training colleges in the country are equipped with computers connected to the Internet. Therefore, many teachers were trained on computers skills during the pre-service training. This was also evident during the training as some of the teachers brought their own laptops of different kinds. Internet could be a problem for many teachers to be able to access the LMS; still, they expect to access the same content in an offline environment via DVDs.

Moreover, it was noted that many teachers own smart phones. This was expected due to the increased number of mobile phone subscribers in the country. A latest Tanzania Communications Regulatory Authority (TCRA) report shows that there are 31 million mobile subscribers in Tanzania accounting to $68 \%$ of total population (Tanzania Communications Regulatory Authority, 2014). Therefore, since the LMS was customized and designed for both computers and mobile devices, it seems teachers believed that they could access the content in LMS via their mobile devices.

Nonetheless, Venkatesh et al., (2011) note that users tend to assess the adequacy of resources (i.e. relevant knowledge and assistance) when they use the technology, thus their pre-usage beliefs associated with facilitating conditions may be disconfirmed. In this regard, those who are involved the implementation of this project should ensure developed content continue to be accessible via mobile devices in order to increase teachers' beliefs.

The study also used social influence to determine the influence of other people such as colleagues or people who are important to them had influence on teachers' acceptance and use of the developed 
content. The study found that social influence had a negative significant effect $(\beta=-.111)$ on teachers' acceptance and use of multimedia-enhanced content. This finding implies that teachers do not perceive that their colleagues or people who are important to them could have an influence on using the content. The training was conducted to few teachers from secondary schools. In other words, not all teachers were retooled with the developed multimedia content. Therefore, none of them expected their colleagues could support them when using the content in their respective schools as most of the teachers did not attend the training.

In order to increase teachers' beliefs, those who are involved in the project implementation should select teachers from the same schools in the next phase of the project. The new teachers will then adjust their pre-usage social influence perceptions because of their observations of the performance in using the content of teachers who previously attended the training.

Another important finding was that hedonic motivation had positive significant effect $(\beta=.347)$ and was the strongest predictor on teachers' acceptance and use of content. This finding shows that teachers perceived the use of the content would be pleasing and enjoyable. The possible explanation of this finding could be the presence of multimedia elements such as animations, audio, and video clips that were integrated into the content. Most of the teachers saw such kinds of the multimedia content for the very first time and they were excited about them.

Therefore, the good feelings and pleasantness derived from using the multimedia content made teachers to believe the content to be useful. Pleasure and arousal can be direct antecedents of behavioral intention, because emotional factors would lead to either approach or avoidance behavioral intention (Xu et al., 2012). To increase this belief, those who are involved in the implementation of the project should develop more multimedia elements in the future to enhance the quality of the content.

The study also found that habit had negative significant effect $(\beta=-.198)$ on teachers' acceptance and use of multimedia-enhanced content. This finding was expected given the fact that teachers believed the content would not easy to use. In addition, habit is built through experience especially when users use the technology for some time. It was not possible for teachers to perceive the use of the content given the fact that the training was also too short.

Finally, performance expectancy was used to determine how much teachers believed that using multimedia content would assist them in improving their teaching. The current study found that performance expectancy did not have a significant effect on teachers' acceptance and use of multimedia-enhanced content. This is contrary to the fact that performance expectancy has been the strongest predictor of acceptance and use of several applications in both voluntary and involuntary environments (Venkatesh et al., 2003).

\section{Conclusion and Suggestions for the Future}

This study set out to determine factors affecting teachers' acceptance and use of developed multimedia-enhanced content in secondary schools in Tanzania using UTAUT2 as a research model. The proposed model accounted for $40.2 \%$ of teachers' acceptance and use of the content. It is therefore clear that there are other factors that contribute teachers' acceptance and use of the content. Future research can add more factors in the model that could be used to explain the acceptance of 
content. Some factors that were used by previous studies include information quality, attitude (Percy \& Belle, 2012), and awareness (Dulle \& Minishi-Majanja, 2011).

With exception of performance expectancy, all other factors had a significant effect on teachers' acceptance and use of the content. The study was based on a quantitative research design with a total of 1,137 teachers who completed the questionnaire. Similar to other quantitative studies, the findings from this study can be generalized to the Tanzania context. However, qualitative study could be adopted in the future in order to find reasons behind teachers' acceptance and use of of multimedia content.

Finally, the findings from this study are based on individual perceptions to the use of multimedia content after they were trained for some time. It should be noted that individual perceptions change over time as users gain experience (Venkatesh et al., 2003). For instance, once teachers used the content for some time, they will gain experience and find the content easy to use. Future research should conduct similar studies using the model in order to apply the findings at a given time. Despite these limitations, this study provides insights on factors that contribute to successful adoption of multimedia-enhanced content in secondary schools in Tanzania.

\section{References}

Avalos, B. (2011). Teacher professional development in teaching and teacher education over ten years. Teaching and Teacher Education, 27(1), 10-20. doi:10.1016/j.tate.2010.08.007

Bagozzi, R. P., \& Lee, K.-H. (2002). Multiple routes for social influence: The role of compliance, internalization, and social identity. Social Psychology Quarterly, 65(3), 226. doi:10.2307/3090121

Cronbach, L. J. (1951). Coefficient alpha and the internal structure of tests. Psychometrika, 16(3), 297-333.

Davis, F. D. (1989). Perceived usefulness, perceived ease of use, and user acceptance of information technology. MIS Quarterly, 13(3), 319-340.

Dulle, F. W., \& Minishi-Majanja, M. K. (2011). The suitability of the unified theory of acceptance and use of technology (UTAUT) model in open access adoption studies. Information Development, 27(1), 32-45. doi:10.1177/0266666910385375

Foster, J. J. (2001). Data analysis using SPSS for Windows versions 8-10: A beginner's guide. Texas: SAGE.

Hair, J. F., Black, W. C., Babin, B. J., \& Anderson, R. E. (2009). Multivariate data analysis (7th ed.). New York: Prentice Hall. 
Hennessy, S., Deaney, R., \& Ruthven, K. (2006). Situated expertise in integrating use of multimedia simulation into secondary science teaching. International Journal of Science Education, 28(7), 701-732. doi:10.1080/09500690500404656

Kaiser, H. F. (1973). An index of factorial simplicity. Psychometrika, 39(1), 31-36. Retrieved from http://eric.ed.gov/?id=EJ105008.

Lanzilotti, R., Ardito, C., Costabile, M. F., \& De Angeli, A. (2006). eLSE methodology : a systematic approach to the e-learning systems evaluation. Educational Technology \& Society, 9(4), 42-53.

Leach, J. (2005). Do new information and communication technologies have a role to play in achieving quality professional development for teachers in the global south? Curriculum Journal, 16(3), 293-329. doi:10.1080/09585170500256495

Lee, Y., Hsiao, C., \& Ho, C.-H. (2014). The effects of various multimedia instructional materials on students' learning responses and outcomes: A comparative experimental study. Computers in Human Behavior, 4O, 119-132. doi:10.1016/j.chb.2014.07.041

Ministry of Education and Vocational Training. (2012). Report and analysis of the results. Dar es Salaam, Tanzania: MoEVT.

Nunnally, J. (1978). Psychometric theory. New York, NY: McGraw-Hill.

Percy, T., \& Van Belle, J.-P. (2012). Exploring the barriers and enablers to the use of open educational resources by university academics in Africa. In I. Hammouda, B. Lundell, T. Mikkonen \& W. Scacchi (Eds.), Open source systems: Long-term sustainability (pp. 112-128). Springer Berlin Heidelberg. doi: 10.1007/978-3-642-33442-9_8

Prestridge, S. (2012). The beliefs behind the teacher that influences their ICT practices. Computers \& Education, 58(1), 449-458. doi:10.1016/j.compedu.2011.08.028

Shulman, L. S. (1987). Knolewledge and teaching: Foundations of the new reform. Harvard Education Review, 57(1), 1-21.

Tanzania Communications Regulatory Authority. (2014). Quarterly communications statistics a quarter ending December 2014. Dar es Salaam, Tanzania: . Retrieved from https://www.tcra.go.tz/images/documents/telecommunication/telcomStatsDec14.pdf

Tanzania science and technology higher education project-additional financing and restructuring. (2014, January 12). Germany Trade and Invest. Retrieved from http://www.gtai.de/

Thomas, O. O., \& Israel, O. O. (2013). Effectiveness of animation and multimedia teaching on students' performance in science subjects. British Journal of Education, Society \& Behavioural Science, 4(2), 201-210. 
Venkatesh, V. (2000). Determinants of perceived ease of use: Integrating control, intrinsic motivation, and emotion into the technology acceptance model. Information Systems Research, $11(4), 342-365$.

Venkatesh, V., Morris, M. G., Hall, M., Davis, G. B., Davis, F. D., \& Walton, S. M. (2003). User acceptance of information technology: Toward a unified view. MIS Quarterly, 27(3), 425-478.

Venkatesh, V., Thong, J. Y. L., Chan, F. K. Y., Hu, P. J. H., \& Brown, S. A. (2011). Extending the twostage information systems continuance model: Incorporating UTAUT predictors and the role of context. Information Systems Journal, 21(6), 527-555. doi:10.1111/j.1365-2575.2011.00373.x

Venkatesh, V., Thong, J. Y. L., \& Xu, X. (2012). Consumer acceptance and use of information technology: Extending the unified theory of acceptance and use of technology. MIS Quarterly, 36(1), 157-178.

Vrasidas, C., \& Glass, G. V. (2007). Teacher professional development and ICT: Strategies and models. Yearbook of the National Society for the Study of Education, 106, 87-102. doi:10.1111/j.17447984.2007.00116.x

Wong, K.-T., Osman, R. b., Goh, P. S. C., \& Rahmat, M. K. (2013). Understanding student teachers ' behavioural intention to use technology: Technology acceptance model (TAM) validation and testing. International Journal of Instruction, 6(1), 89-104.

Xu, L., Lin, J., \& Chan, H. C. (2012). The moderating effects of utilitarian and hedonic values on information technology continuance. ACM Transactions on Computer-Human Interaction (TOCHI), 19(2).

\section{Athabasca \\ University}

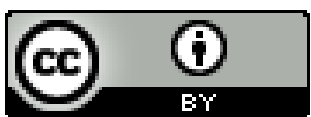

